\title{
Hopping fences
}

Just how proteins jostle around in the fatty membrane that

surrounds every living cell has been a source of debate for decades. Now one researcher is using an ultra-highspeed camera to watch this dance in unprecedented detail but that hasn't stopped the arguments. Alison Abbott investigates.

W hen Akihiro Kusumi ran his grainy black-and-white film of a single molecule dancing maniacally against a grey background, a wave of confusion passed through the audience. Those seeing the pictures for the first time gaped in amazement and scepticism. Questions were fired from the floor. What exactly is being measured? How did you do it? Can you really catch the rapid movements of such a molecule on film?

At this conference in Italy last autumn, Kusumi was claiming to show the movement of a protein within the lipid membrane of a living mammalian cell, on microsecond and nanometre scales. In decades of membrane research, no one else has come close to such a precise level of visualization.

Kusumi's analyses have led him to propose a sweeping hypothesis for cell membrane dynamics, which he calls 'hop diffusion'. He suggests that molecules move around in the membrane at breakneck speed, but are confined in small areas by 'fences' created by the cell's actin cytoskeleton - a mesh of filaments that helps give a cell its shape. Occasionally the molecules hop over these fences, and so seem to travel over larger distances at a relatively sedate rate (see 'Fenced in',opposite).

This rather simple idea may not sound

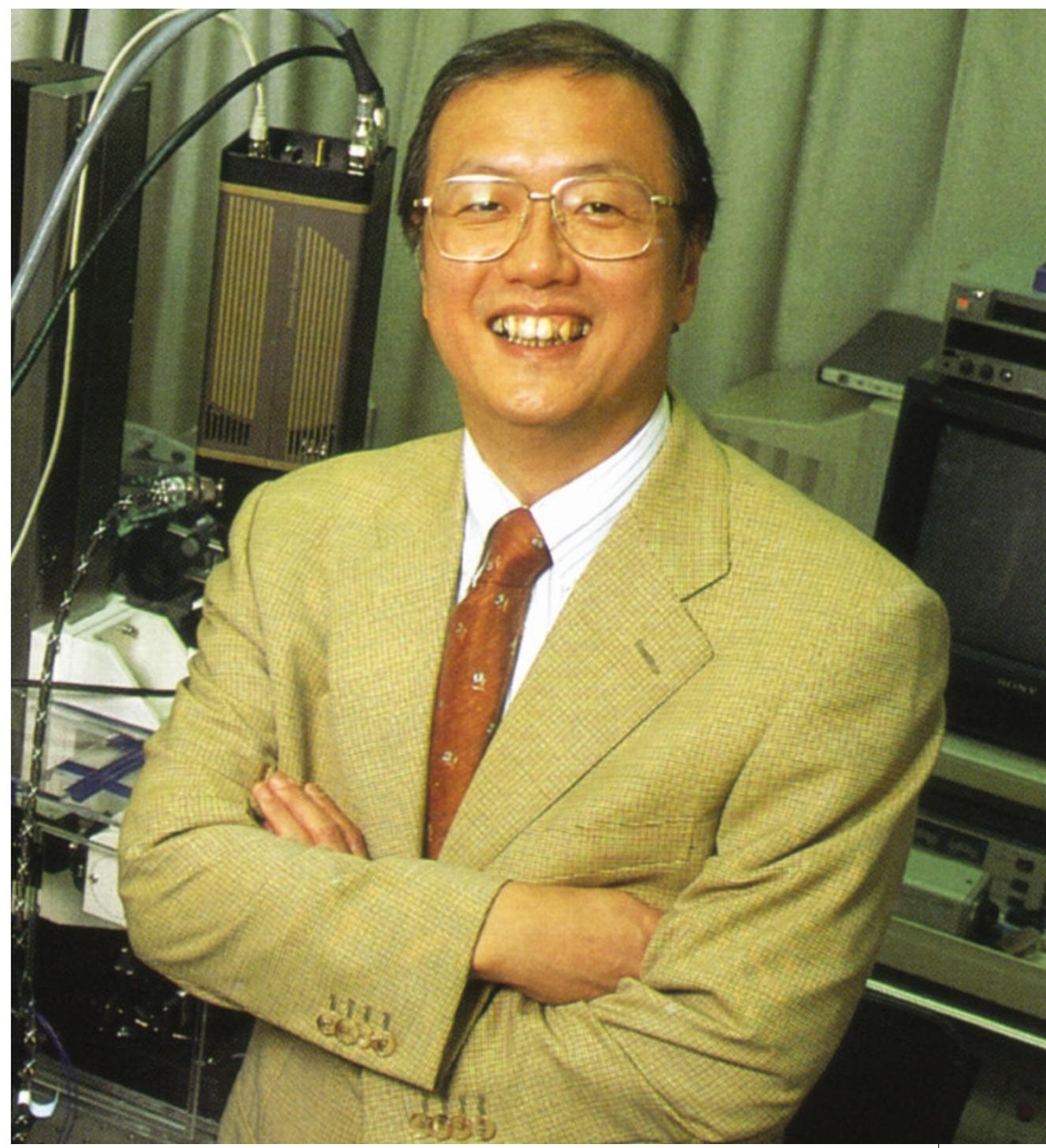

Caught on camera: Akihiro Kusumi believes he has filmed proteins moving in cell membranes.

like a bombshell, but it is causing a sensation in the world of membrane biophysics. If true, the concept would solve some long-standing puzzles about how proteins move within a membrane. Perhaps more important, it would also shed light on how signals from the outside world are transmitted through the membrane to the inside of the cell - a process that is central to cell behaviour in health and disease. Working out the details of signal transduction is one of today's major challenges. Cell and molecular biologists have spent years identifying which proteins in a cell membrane need to bind together to convey a signal, but they have not been able to explain how these proteins manage to meet and interact so successfully.

Kusumi's work has been controversial among the cognoscenti for some years, and in the past he has had problems getting published. This was partly a consequence of his interdisciplinary approach, which brought into the field new technologies that no one else was able to acquire - most pertinently ultrafast filming technology borrowed from the field of explosion research. In the past few years his work has gained greater acceptance, although there are still those who argue with his bold interpretations of his data.

\section{Movie maker}

Kusumi, who has recently moved to the University of Kyoto, is relentlessly cheerful, and seems to take attacks on the chin, ploughing happily on and finding humour in every situation. Like the molecules he studies, he does not like to be too confined. And he certainly does not want to be placed in a tight scientific box. "I studied both physics and biology as an undergraduate and did my PhD in biophysics," he says. "People like to think that I spend most of my time working with machines, but in fact I spend most of my time thinking about biology." Such credentials, he indicates, have helped him to bridge the parallel worlds of biophysics and cell biology.

Hebegan his independent research career in the early 1980s. Then, the working hypothesis for membrane dynamics was the 


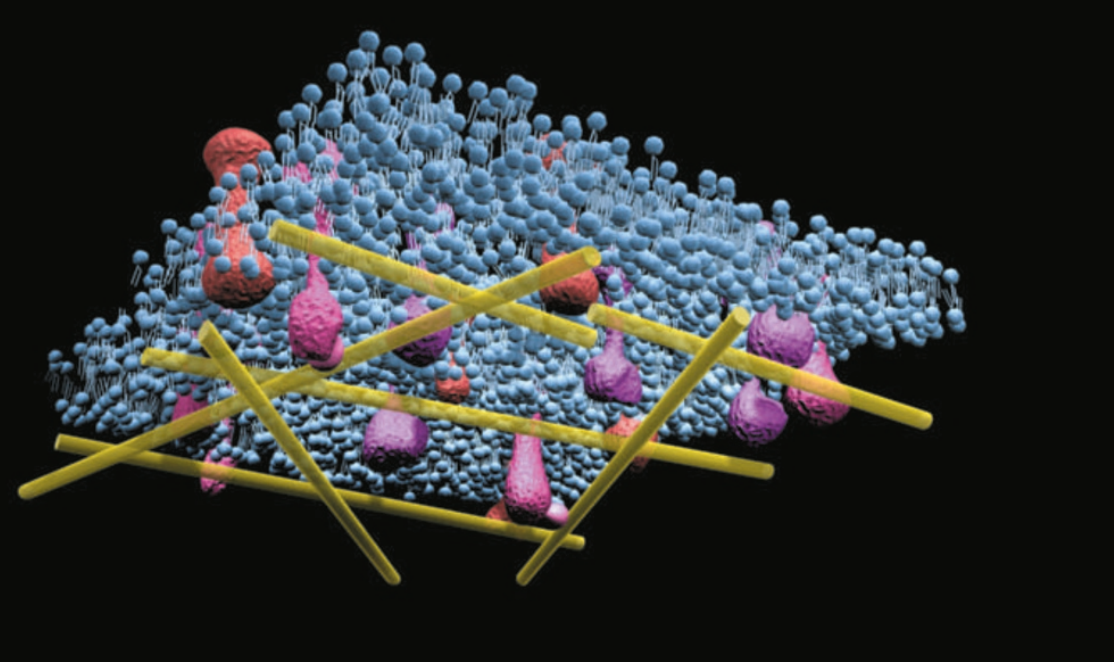

Cell membrane structure: a variety of proteins are held in a double layer of lipids (blue). It is possible that the underlying actin cytoskeleton of the cell (yellow) confines the movement of the proteins.

1972 'fluid mosaic model', which described membranes as a double layer of lipids that holds protein molecules (see picture, above). Some of the proteins pass from outside the cell right the way through the 'lipid bilayer' into the cell's inside; others sit in just the outer lipid layer poking their heads outside the cell membrane. Yet others nuzzle onto or into the inner layer of lipids from within the cell. The membrane proteins are not fixed but, according to this theory, can diffuse freely around in their lipid environment through brownian motion - the random movement of atoms and molecules due to thermal energy.

This structural picture, which is still believed to be broadly true, is supported by biochemical and microscopic evidence ${ }^{1}$. But there are serious problems with the idea that brownian motion alone is responsible for the movement in a cell membrane.

In the 1980s, it became clear to biophysicists that proteins in living cells moved within the membrane up to 100 times slower than they did in artificial membranes simple lipid constructions made in the lab. Something, they reasoned, must be constraining the free diffusion of proteins in natural, living membranes.

\section{Hidden depths}

Cell biologists, meanwhile, had a problem with the very concept of proteins moving by free diffusion — it didn't square with new information about the function of membrane proteins. Many membrane proteins are involved in the complex business of cellular signalling. A common signal is the binding of a hormone or a growth factor to the part of a membrane-spanning receptor protein sticking outside of a cell. The binding causes the receptor to change shape, sparking a sequence of interactions with other proteins in the lipids that allows the message to be carried to the appropriate machinery inside the cell.

Cell and molecular biologists identified a large number of such proteins in different signalling pathways, and by the 1990s they were no longer convinced that free diffusion was sufficient to explain how the right lineup of proteins arrived in the right place at the right time to guarantee interaction. It was becoming clear that a higher order of organi-

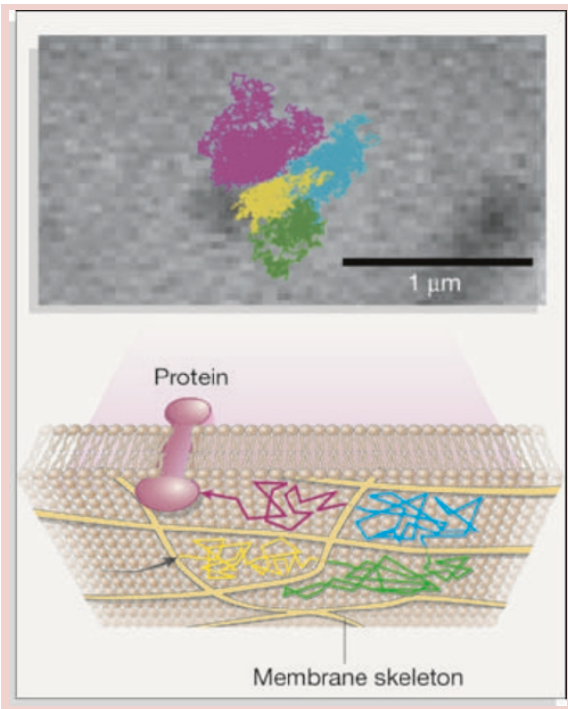

\section{Fenced in}

Akihiro Kusumi's hypothesis proposes that the cell's internal skeleton (yellow) acts like a fence on the inner side of the cell membrane. A protein races around within one fenced-off section at high speed, before hopping the fence into another section. The evidence is shown in the photo above, which combines tens of thousands of snapshots to show the protein's location over a period of a second or so. Kusumi has joined the dots of the protein's journey with a colour for each fence-posted area. zation in the membrane was called for to constrain the signalling molecules.

Enter the 'lipid raft hypothesis', which proposed that protein movement could be constrained by the physicochemical properties of different mixtures of lipids. According to this idea, the various lipids in a cell membrane are not randomly distributed, as previously supposed, but can group into clusters that are more viscous than the rest of the membrane ${ }^{2}$. These floating rafts of specific types of lipid provide favourable environments for certain proteins, and so effectively confine them to a limited area. The coming together of several small rafts during signalling initiation would then get all the right proteins into the same place at the same time.

The raft hypothesis was a godsend for those developing ideas about the dynamics of cell signalling. But there are sceptics. Although rafts have apparently been seen under the microscope, most evidence for their existence is indirect, and some believe that they are an artefact of the way the cells are prepared for analysis. Someone has even coined the term 'unidentified floating objects' for them.

\section{Cells on film}

But if rafts are not the answer, what else could confine protein molecules to a small space for long enough to allow the appropriate interactions to take place? Kusumi decided that the only way forward was to study the movement of single molecules. He found a way to attach a colloidal gold particle, 20-40 nanometres in diameter, to a membrane protein and video its movement. Using a rat kidney cell he made his first observation of apparent hop diffusion ${ }^{3}$. The gold particle whizzed around in a small area of the membrane and then seemed to jump into a neighbouring area, rather than moving randomly at a more sedate speed throughout the whole membrane or being confined to a raft.

He reasoned that the compartments could be defined by fences made from actin filaments of the cytoskeleton within the cell pushing against the underside of the membrane. This concept extended the theoretical work of Michael Sheetz, a biophysicist at Columbia University in New York, who in 1983 had first proposed that transmembrane proteins might be constrained by the cytoskeletal network in red blood cells ${ }^{4}$.

But when Kusumi looked for hopping in many other types of cells, including red blood cells, he couldn't find it. His data showed proteins that seemed to move freely around the membrane, without lingering in areas between supposed fences. He knew that his camera's spatial resolution was good enough to pick up the expected jittering movement within confined areas; but maybe, he thought, it wasn't quick enough.

To find out, he needed a faster camera - 
much faster. "I was certain that explosion researchers would be using very fast cameras. I remembered that scientists developing the atomic bomb in the Manhattan project used them to observe explosions," he says. He found several modern models on the market, but they were for areas such as explosion research and were not specifically designed for microscopic work.

Kusumi acquired one anyway, which at 40,000 frames per second gave a 25microsecond resolution - 1,000 times faster than his previous camera. "We had to integrate the camera with our microscopes and then optimize the system through a lot of tinkering," he says. 'Tinkering' is too small a word for what was required, which included improving contrast, introducing a light source that kept the camera, the microscope and the cells happy, and, most important, speeding up data analysis. Kusumi says that without his multidisciplinary team of 20 researchers, ranging from computer scientists to physicists and biochemists, it would not have been possible to create the complex machine that takes his apparently simple films.

\section{Hop and glory}

With the new system in place, his team was soon seeing what looked like hop diffusion in many different types of cell. On average the group would see a hop every 1-1,000 milliseconds and membrane compartments of about 30-200 nanometres across. This explained the difference between diffusion speeds in natural membranes and artificial ones. Proteins move at the same fast speed in both, but their progress is hindered by fences in the natural system, making their long-distance diffusion slower. "The hops were being missed in video recording, which has a resolution of only 30 milliseconds," says Kusumi. "A lot can happen in 30 milliseconds."

"We were delighted, but we still knew that an enigma remained," says Kusumi. It is not just proteins within the membrane that move - the lipids move too. And these also seem to diffuse more slowly in natural cells than in artificial systems, even though the outer layer of lipids is well out of reach of the cell skeleton underneath.

It proved much harder to label and track lipids compared with proteins. But after two years and thousands of films, Kusumi succeeded in getting statistically sound results, showing lipids hopping too ${ }^{5}$ - they move, he found, at a rate of one hop every 1-100 milliseconds. This, he thinks, is because some proteins that pass right through the membrane are anchored against the cytoskeletal fence, and so act as fence posts or pickets. These mark out corrals that help to confine the membrane lipids.
In 2001, Kusumi began to present his results, his interpretation and his general view of how a membrane keeps its house in order. At the same time, other work from his lab was adding weight to his theory ${ }^{6}$. Experiments with electron microscope computed tomography of the cytoskeleton, sophisticated spectroscopes and other high-tech instruments such as molecular tweezers ${ }^{7}$, he says, corroborated the size of the fenced-in corrals. And, Kusumi adds, the force required to drag a molecule over a fence is in line with what the hypothesis would predict. What he did not see was

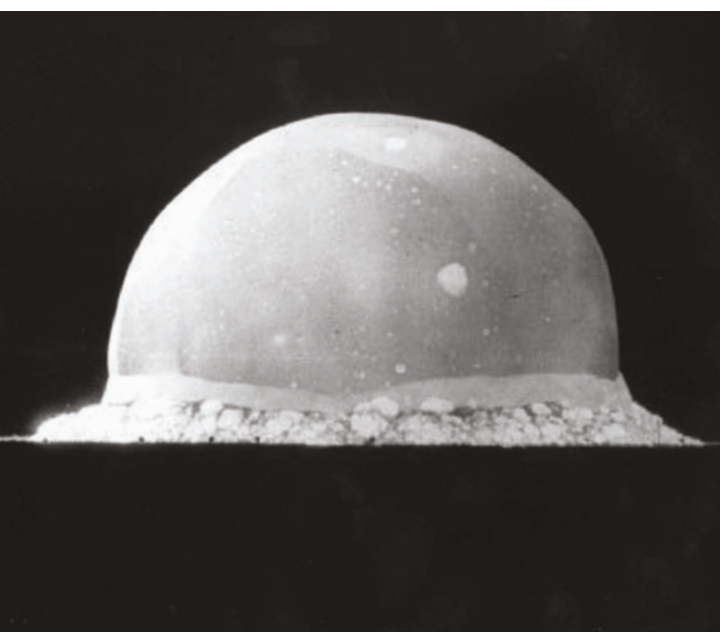

A nuclear explosion after 0.16 seconds, caught on camera in 1945. milar techniques are now being used to image cell molecules. that somehow a 40-nanometre particle may be affecting the results in some way."

There are rivals to the fence-and-picket model that might explain the curious dynamics that Kusumi observes, adds Jitu Mayor, a cell biologist at the National Centre for Biological Sciences in Bangalore. Some scientists argue that the simple crowding of proteins in living membranes could account for the relatively slow protein movement, he says. But Mayor argues that no one else has tackled the problems as thoroughly as Kusumi, coming up with a broad, internally consistent hypothesis and then working to validate it. "The rivals just don't make testable predictions," he says.

Kusumi is not only dedicated to putting his theory through the wringer of experiment; he is also willing to sit on the fence over the question of rafts. Once a cell has begun the process of cell signalling - after the proteins required have already come together - he says he does see some evidence for the raft hypothesis. "We see molecules forming clusters when they are stimulated by a signal, so they can be seen as rafts," he says, referring to unpublished work. "But we don't see them in non-stimulated cell membranes."

Kai Simons, a director at the Max Planck Society for cell biology in Dresden, Germany, and one of the strongest proponents of raft theory, is evidence that rafts played any part in initiating cell signalling.

Kusumi's grand hypothesis, created with self-assembled high-tech equipment, really shook things up. "There is no doubt that Kusumi has had a dramatic effect on the field of membrane biophysics," says Ken Jacobson, a cell biologist at the University of North Carolina at Chapel Hill. "He has pushed the field on several fronts.”

Jacobson, who also tracks single particles in cell membranes, but using a slower-speed video camera, comments that Kusumi's hop-diffusion model has been accepted to a "modest degree" in the field. One of the major obstacles to full acceptance, he says, is that no other lab currently has the high-speed equipment to confirm the results independently.

\section{Golden retriever}

Another worry is the use of a relatively large gold particle for tracking - a particle that may be larger than some of the corrals. Kusumi argues that he carries out extensive, time-consuming control studies to ensure that the dot of gold is pulling only a single molecule. In his research community Kusumi is known for his obsessive rigour most people have the greatest confidence in his technical prowess, says Jacobson. "But even so, you always have that nagging doubt mollified by this. If Kusumi can't see rafts before cell signalling, says Simons, perhaps that's because the gold particle is perturbing the system too much. In the case of stimulated cell membranes, he says, he and Kusumi are happily in agreement.

Kusumi takes his critics seriously. But he laughs about it too, throwing out asides: "new ideas can be difficult," he says, and "physicists are fond of brownian motion."

So Kusumi will forge ahead, extending his work to look at the interactions between cell membrane proteins and nanomaterials being developed for tissue transplantation. Nagoya to a new centre, whose name reflects his tendency to work at the edge: the University of Kyoto's Institute of Frontier Medical Sciences. It isn't the first time Kusumi has shifted his workplace - he has moved once every eight years to a new city. "I lead my life according to hop-diffusion principles," he laughs. Thankfully, he's easier to catch on camera.

Alison Abbott is Nature's senior European correspondent.

1. Edidin, M. Nature Rev. Mol. Cell Biol. 4, 414-418 (2003).

2. Simons, K. \& Ikonen, E. Nature 387, 569-572 (1997).

3. Kusumi, A., Sako, Y. \& Yamamoto, M. Biophys. J. 65, 2021-2040 (1993).

5. Murase, K. et al. Biophys. J. 86, 4075-4093 (2004)

6. Kawasaki, K., Yin, J. J., Subczynski, W. K., Hyde, J. S. \&

Kusumi, A. Biophys. J. 80, 738-748 (2001). He has just moved from the University of

4. Sheetz, M. P. Semin. Hematol. 20, 175-188 (1983).

7. Nakada, C. et al. Nature Cell Biol. 5, 626-632 (2003). 